\title{
Intravenous paracetamol vs. ketoprofen for pain management after the abdominal aortic surgery - pharmacokinetics and therapeutics
}

\author{
Jowita Rosada-Kurasińska', Alicja Bartkowska-Śniatkowska', Agnieszka Bienert² \\ Małgorzata Grześkowiak ${ }^{3}$, Paweł Sobczyński ${ }^{4}$, Marzena Zielińska ${ }^{5}$ \\ ${ }^{1}$ Department of Pediatric Anesthesiology and Intensive Therapy, Poznan University of Medical Sciences, Poland \\ ${ }^{2}$ Department of Clinical Pharmacy and Biopharmacy, Poznan University of Medical Sciences, Poland \\ ${ }^{3}$ Department of Teaching Anesthesiology and Intensive Therapy, Poznan University of Medical Sciences, Poland \\ ${ }^{4} 1^{\text {st }}$ Department of Anesthesiology and Intensive Therapy, Poznan University of Medical Sciences, Poland \\ ${ }^{5}$ Department of Anesthesiology and Intensive Care, Pediatric Intensive Care Unit, Wroclaw Medical University, Poland
}

\section{ABSTRACT}

Introduction. Acute postoperative pain continues to be a dilemma to patients and clinicians.

Aim. To define the efficacy, tolerability and pharmacokinetics of paracetamol and ketoprofen in patients after the abdominal aortic surgery. Setting and design in University hospital - intensive therapy unit (clinical part), clinical pharmacy and biopharmacy unit (biochemical part), and pharmaceutical company (statistical part). Prospective randomized study.

Material and Methods. 40 adult patients (50-84 years) undergoing abdominal aortic surgery were randomized equally into two groups. After extubation the patients in group 1 (G1) were administered a $1 \mathrm{~g}$ paracetamol infusion, and in group 2 (G2) - a 100 mg ketoprofen infusion, both within 15 minutes. All the patients received an epidural infusion of bupivacaine with fentanyl. The following parameters were recorded: mean arterial pressure (MAP), heart rate (HR), central venous pressure (CVP), plasma concentration of paracetamol and ketoprofen. Postoperative pain was assessed with the visual analogue scale (VAS).

Results. The mean values of the MAP, HR and CVP were within normal limits in the both groups. No significant differences were noticed in the assessment of postoperative pain and total use of an opioid. The mean therapeutic plasma concentration of paracetamol and ketoprofen remained up to 180 minutes and up to 120 minutes, respecively.

Conclusions. The study enabled us to conclude that intravenous paracetamol as well as ketoprofen have good effectiveness and tolerability. There is no need to modify dosage of these drugs to elderly patients. After paracetamol infusion the therapeutic plasma concentration remains longer than after the ketoprofen infusion.

Keywords: paracetamol, ketoprofen, postoperative pain, pharmacokinetics.

\section{Introduction}

In spite of considerable progress in pain therapy the effective treatment of acute postoperative pain continues to be a dilemma to patients and clinicians. It is estimated that in about two thirds of patients the alle- viation of postoperative pain is insufficient and pain becomes the cause of unnecessary suffering [1].

The intensive development of pharmacology enabled the introduction of multimodal analgesia. This is a method of analgesic treatment which consists of connecting different techniques of local anaesthesia 
with combination pharmacotherapy. It enables both the use of the additive and synergistic effects of individual drugs, considerable reduction in the dosage of those drugs as well as reduction in the frequency of adverse reactions occurrence [2].

In view of those facts, apart from opioids the clinical practice of postoperative pain treatment also applies non-steroidal anti-inflammatory drugs and paracetamol, the latter of which is widely used in outpatient medical practice. At present, thanks to the new intravenous formula it can also be applied to patients after surgeries. The recommendations for postoperative pain treatment after the surgeries with considerable tissue trauma include intravenous patient controlled analgesia (PCA) and the techniques of regional analgesia, such as continuous epidural analgesia [3].

Intravenous paracetamol (also known as acetaminophen) is an analgesic and antipyretic substance, recommended worldwide as a first-line agent for the treatment of pain and fever in adults and children [4] The availability of intravenous paracetamol (Perfalgan $^{\oplus}$, Ofirmev $^{\otimes}$ ) has greatly extended the use of this drug in the intensive care settings [5].

Ketoprofen is a non-steroidal anti-inflammatory drug with a strong anti-inflammatory, analgesic and antipyretic effect. In chemical terms it is a 2-(3benzoylphenyl)-propionic acid, available in the intravenous, intramuscular, oral, rectal and percutaneous form [6] The intravenous form is the most suitable and practical for administration in the postoperative period. Ketoprofen was synthesised by the chemists from Rhone-Poulenc company in 1967, 3 years after its prototype - ibuprofen [7] Intravenous ketoprofen is chiefly used for short-term treatment of postoperative pain.

In spite of the fact that intravenous paracetamol is more and more widely applied in clinical practice, the data comparing the clinical efficacy, safety and clinical pharmacokinetics of this drug with other analgesics are limited [8] Vascular surgery patients present a formidable challenge to the practising intensivist. These patients are often at an advanced age and carry significant cardiac, respiratory, and renal co-morbidities [9] Among different types of non-cardiac surgery, peripheral vascular surgery is likely to have the highest cardiac morbidity and overall mortality.

The purpose of this study was to define the clinical tolerability of paracetamol and ketoprofen in patients after the abdominal aortic surgery, the dosage profile of these drugs to this population of patients and the clinical pharmacokinetics with influence on the postoperative analgesic effect.

\section{Material and Methods}

After obtaining institutional Bioethics Committee approval, this research was conducted in the intensive care unit (ICU) of the University Hospital. Written informed consent was obtained from all included patients. Forty patients (50-84 years old, 7 females, 33 males, ASA 3-4) qualified for reconstruction of the abdominal part of the aorta due to aortic aneurysms or chronic aortoiliac occlusive disease were included into the study. The patients were randomly divided into two groups. After the extubation group I (G1) received an intravenous infusion of paracetamol (Perfalgan ${ }^{\circledR}$, Bristol-Myers Squibb, Anagni, Italy) and group II (G2) received ketoprofen (Ketonal ${ }^{\circledR}$, Lek, Ljubljana, Slovenia). The patients with liver and renal dysfunction or with a documented allergy to the medication were excluded from the survey. All the patients received $10-20 \mathrm{mg}$ of temazepam 60 minutes before the surgery. Anaesthesia was induced intravenously by infusion of etomidate $0.1 \mathrm{mg} / \mathrm{kg}$ and fentanyl $3 \mu \mathrm{g} / \mathrm{kg}$, with muscle relaxation induced by pancuronium $0.1 \mathrm{mg} / \mathrm{kg}$. Then the patients were intubated and received one dose of fentanyl 0.1 $\mathrm{mg}$ in $10 \mathrm{ml} 0.9 \% \mathrm{NaCl}$ and constant infusion of $0.125 \%$ bupivacaine $5 \mathrm{ml} / \mathrm{h}$ into the lumbar epidural space (L2-L3 or L3-L4) through a catheter (16G) inserted to all the patients the day before anaesthesia.

Anaesthesia was maintained with up to $1.5 \mathrm{MAC}$ of volatile anaesthetic isoflurane in a mixture of oxygen and air $\left(\mathrm{FiO}_{2} \mathrm{0.4}\right)$ in a low-flow circuit (fresh gas flow of $1 \mathrm{l} / \mathrm{min}$ ), with fentanyl in boluses of $0.1 \mathrm{mg}$ and pancuronium $0.03 \mathrm{mg} / \mathrm{kg}$ and with a constant infusion of bupivacaine into the epidural space.

Just after the operation the patients were admitted into the ICU. After the extubation G1 (20 patients) received an intravenous infusion of paracetamol $(1 \mathrm{~g}$ within 15 minutes) and $\mathrm{G} 2$ received an intravenous infusion of ketoprofen (100 $\mathrm{mg}$ in $100 \mathrm{ml}$ of $0.9 \% \mathrm{NaCl}$ within 15 minutes). Apart from the above-mentioned medications the patients in both groups were applied a constant infusion of $0.125 \%$ bupivacaine with fentanyl $2 \mu \mathrm{g} / \mathrm{ml}$ into the epidural space at a rate of 5-8 $\mathrm{ml} / \mathrm{h}$. An opioid (pethidine) was also applied in the patient-controlled anaesthesia (PCA) system. This protocol has been applicable according to therapeutic standard in the department.

All the patients were constantly monitored for the mean arterial pressure (MAP), heart rate (HR) and central venous pressure (CVP). In G1 the concentration of paracetamol and in $\mathrm{G} 2$ the concentration of ketoprofen were measured. All the measurements listed above 
were made before the infusion of the medications under study (paracetamol and ketoprofen) after extubation - T0, immediately after the end of the infusion $\mathrm{T} 1$, and 5 - T2, 15 - T3, $30-\mathrm{T} 4,60-\mathrm{T} 5,120-\mathrm{T} 6,180$ - T7, $240-\mathrm{T} 8,300-\mathrm{T} 9$ and 360 minutes - T10 after the end of the infusion. The pharmacokinetic parameters of the medications were assessed. The total dose of an opioid used in the PCA system was also measured during the study.

Apart from that, the side effects of the early postoperative period were also monitored, such as the haemodynamic changes (with a cardiac monitor IntelliVue MP60, Phillips), allergic reactions and others.

Arterial blood $(3 \mathrm{ml})$ was taken from an arterial cannula in the radial artery. After centrifuging the plasma was frozen and stored at $-20^{\circ} \mathrm{C}$ until all the material from a particular cycle of the research was collected.

At each point of time (TO-T10) the mean, minimum and maximum concentrations of the medications were analysed. The correlations between the main concentration of paracetamol and the visual analogue scale (VAS) median in $\mathrm{G} 1$ and between ketoprofen and the VAS median in $\mathrm{G} 2$ were estimated. The values of the pharmacokinetic parameters of paracetamol and ketoprofen were calculated on the basis of a model-independent pharmacokinetic approach. The multifactor analysis of covariance based on the linear model of coexisting variables was used to estimate the influence of body weight and age on the pharmacokinetic parameters of the medications.

The paracetamol plasma concentrations were measured with a TDx apparatus (Abbott Diagnostic Division USA, 1996; Abbott/Shaw Lifecare Infusion
Pump, Model 3) by means of the fluorescence polarisation immunoassay (FPIA).

The ketoprofen concentration in the plasma was measured by means of high-performance liquid chromatography with an ultraviolet detector $\left[{ }^{[}[10]\right.$ ] The quantification limit was estimated at $0.05 \mathrm{mg} / \mathrm{l}$. The within-day and between-day coefficients of variation were lower than $10 \%$.

Both ketoprofen and paracetamol pharmacokinetic parameters were calculated by means of the non-compartmental (NCA) model with Phoenix ${ }^{\mathrm{TM}}$ WinNonlin $^{\circledR}$ 6.3 (Certara L.P.). The area under the plasma concentration-time curve (AUC) from time 0 to the last sampling point was calculated by means of the linear trapezoidal linear interpolation method. The elimination half-life $\left(t_{1 / 2}\right)$ was estimated from the last four plasma concentration time points. The NCA model was used to calculate the following pharmacokinetic parameters for paracetamol and ketoprofen: area under the plasma concentration-time curve from time zero to infinity $\left(A \cup C_{\infty}\right)$, elimination half-life $\left(t_{1 / 2}\right)$, clearance $(C L)$, volume of distribution $(\mathrm{Vd})$, and mean residence time $\left(\mathrm{MRT}_{\infty}\right)$

\section{Statistical analysis}

Age, body weight, height, MAP, HR, CVP and the total consumption of an opioid were described as the mean value with the standard deviation (Tables 1 and 2). The Shapiro-Wilk test was used to check the consistence with the normal distribution. The t-Student test was used to compare the two groups of measurements (paracetamol vs. ketoprofen) for independent trials

Table 1. The demographic data, classification of physical state, indications for surgery and total dose of an opioid as means with standard deviations

\begin{tabular}{lcc}
\hline \multicolumn{1}{c}{ Parameters } & $\begin{array}{c}\text { G1 } \\
\text { (paracetamol) }\end{array}$ & $\begin{array}{c}\text { G2 } \\
\text { (ketoprofen) }\end{array}$ \\
\hline Age (years) & $63.9 \pm 7.08$ & $64.7 \pm 8.96$ \\
\hline Sex (M/F) & $15 / 5$ & $18 / 2$ \\
\hline Body weight (kg) & $75.55 \pm 16,89$ & $76.8 \pm 15.97$ \\
\hline Height (cm) & $170.94 \pm 7.15$ & $171.88 \pm 10.47$ \\
\hline Body mass index (BMI) & $25.6 \pm 5.66$ & $25.81 \pm 4.96$ \\
\hline Classification of physical state (ASA) & & \\
- III & 14 & 15 \\
- IV & 6 & 5 \\
\hline Diagnosis: & 12 & 11 \\
- aneurysm & 7 & 7 \\
- Lerich syndrom & 1 & 2 \\
- aneurysm and Lerich syndrom & & \\
\hline Total consumption of pethidine dose (mg) & 14 & 16 \\
- number of patients $(\mathrm{n})$ & $33.1 \pm 27.9$ & $30.5 \pm 26.8$ \\
- mean \pm SD & & \\
\hline
\end{tabular}

None $\mathrm{p}$ correlations were found between the groups 
Table 2. The results of hemodynamic parameters as means and standard deviations

\begin{tabular}{|c|c|c|c|c|c|c|}
\hline \multirow{2}{*}{$\begin{array}{c}\text { Parameters } \\
\text { Group } \\
\text { Time points }\end{array}$} & \multicolumn{2}{|c|}{ MAP [mmHg] } & \multicolumn{2}{|c|}{ HR [beats/min] } & \multicolumn{2}{|c|}{ CVP $\left[\mathrm{cmH}_{2} \mathrm{O}\right]$} \\
\hline & $\begin{array}{c}\mathrm{G} 1 \\
\text { (paracetamol) }\end{array}$ & $\begin{array}{c}\text { G2 } \\
\text { (ketoprofen) }\end{array}$ & $\begin{array}{c}\mathrm{G} 1 \\
\text { (paracetamol) }\end{array}$ & $\begin{array}{c}\text { G2 } \\
\text { (ketoprofen) }\end{array}$ & $\begin{array}{c}\mathrm{G} 1 \\
\text { (paracetamol) }\end{array}$ & $\begin{array}{c}\text { G2 } \\
\text { (ketoprofen) }\end{array}$ \\
\hline TO & $105.1 \pm 14.6$ & $95.7 \pm 11.6^{\#}$ & $84.7 \pm 14.0$ & $87.7 \pm 14.8$ & $6.6 \pm 3.1$ & $7.4 \pm 2.1$ \\
\hline $\mathrm{T} 1$ & $97.7 \pm 13.6$ * & $88.6 \pm 13.4^{\#}$ & $82.6 \pm 11.2$ & $84.0 \pm 14.2$ & $6.4 \pm 3.1$ & $7.2 \pm 2.1$ \\
\hline $\mathrm{T} 2$ & $94.8 \pm 13.0$ * & $86.8 \pm 14.4$ & $82.4 \pm 11.1$ & $84.8 \pm 14.6$ & $6.2 \pm 2.8$ & $6.7 \pm 2.0$ \\
\hline T3 & $94.1 \pm 13.9 *$ & $84.8 \pm 14.3^{\#}$ & $82.7 \pm 12.7$ & $82.3 \pm 14.1 *$ & $5.7 \pm 2.5$ & $6.2 \pm 2.3$ \\
\hline T4 & $94.3 \pm 13.7 *$ & $82.3 \pm 13.9^{\#}$ & $82.9 \pm 11.0$ & $83.8 \pm 14.1$ & $5.7 \pm 2.5$ & $6.1 \pm 2.4$ \\
\hline T5 & $90.9 \pm 13.1 *$ & $83.2 \pm 11.7$ & $83.0 \pm 11.6$ & $82.3 \pm 13.8 *$ & $5.8 \pm 2.1$ & $6.7 \pm 2.4$ \\
\hline T6 & $92.5 \pm 14.3 *$ & $82.7 \pm 11.8^{\#}$ & $80.1 \pm 11.2$ & $82.7 \pm 13.9$ & $5.2 \pm 2.7$ & $7.2 \pm 2.4^{\#}$ \\
\hline $\mathrm{T7}$ & $91.1 \pm 14.3 *$ & $81.2 \pm 13.0^{\#}$ & $81.8 \pm 11.1$ & $82.2 \pm 13.4 *$ & $5.5 \pm 2.5$ & $7.4 \pm 3.2^{\#}$ \\
\hline T8 & $93.8 \pm 15.4 *$ & $83.3 \pm 13.7^{\#}$ & $83.8 \pm 10.1$ & $81.9 \pm 13.3 *$ & $4.9 \pm 2.4$ & $7.6 \pm 2.9^{\#}$ \\
\hline T9 & $95.2 \pm 14.0$ * & $82.3 \pm 14.8^{\#}$ & $81.5 \pm 12.0$ & $81.0 \pm 12.8^{*}$ & $5.6 \pm 2.4$ & $7.7 \pm 3.4^{\#}$ \\
\hline T10 & $94.2 \pm 14.6 *$ & $83.2 \pm 12.3^{\#}$ & $80.8 \pm 10.8$ & $81.5 \pm 13.3^{*}$ & $5.2 \pm 2.5$ & $8.2 \pm 3.7^{\#}$ \\
\hline
\end{tabular}

MAP - mean arterial pressure, HR - heart rate, CVP - central venous pressure

* The statistically significant difference within one group $(p<0.05)$

\# The statistically significant difference between both groups $(p<0.05)$

when consistence with the normal distribution was present. If not, the Mann-Whitney test was chosen.

The analysis of variance (ANOVA) was used for repeatable measurements at the 11 time periods with the Tukey post-hoc test for the distribution of data compatible with the normal distribution.

The parameters presented on a serial scale as VAS were described with the median, minimum and maximum values. For confirmation of the two groups the Student t-test or Mann-Whitney test were used for independent trials.

For the assessment of consistence between the concentration of the drug and the VAS the Spearman factor of non-parametric correlation was used.

The statistical analysis was made with specific software (Statistica, version 8.0.), $p$-values $<0.05$ were considered statistically significant.

The influence of body weight and age on the pharmacokinetic parameters of the drugs was estimated by means of the multifactor analysis of covariance based on a linear model including the patient's body weight and age as coexisting variables. The measurements were made with the PROC GLM procedure of the statistical package SAS (SAS Institute Inc. 2002-2003. The SAS System for Windows v. 9.1.3, Service Pack 4, Cary, NC, USA).

\section{Results}

No one of 40 patients resigned or was excluded from the study. The assessed groups were homogeneous. There were no differences in the demographic param- eters or the risk of operation. The majority of patients was categorized as the class III of ASA scale. The mean of total PCA pethidine consumption in $\mathrm{G} 1$ and $\mathrm{G} 2$ was $33.1 \mathrm{mg}$ and $30.5 \mathrm{mg}$ respectively, and did not significantly differ between both groups (Table 1).

The mean values of hemodynamic parameters (MAP, HR and CVP) are presented in (Table 2). The distinguish changes between both groups were observed for MAP (throughout the whole sampling time) and CVP (from T6 to T10 sampling time). With respect to HR, the only few results in the ketoprofen group were recognized as statistically significant within that group.

The values of VAS score obtained from patients' interview are described in (Table 3) as median, minimum and maximum measurements, for both group and at each sampling time (TO - T10). The median of VAS values decreased in similar way in both groups throughout the whole sampling time. It reduced from 4.5 to 2.0 and 5.5 to 1.0 for $\mathrm{G} 1$ and $\mathrm{G} 2$, respectively. The minimum values were almost the same in both groups at corresponding sampling points. Of note, the maximum results were comparable only from TO to T4. Maximum values at T5, T6, T9 and T10 were lower for paracetamol group, whereas results at $\mathrm{T} 7$ and $\mathrm{T} 8$ slightly favored ketoprofen. Increase of maximum VAS results in both groups at the last sampling time points (T9 and T10) may be related with the end of therapeutic concentrations estimated for both drugs (Figures 1, 2 and 3 ).

Basic pharmacokinetic parameters for both drugs were investigated (Table 4). With respect to paracetamol, of note, much higher values of $\mathrm{AUC}_{\infty}, \mathrm{Vd}, \mathrm{CL}$ and $\mathrm{MRT}_{\infty}$ 
Table 3. Values of VAS score in the paracetamol group (G1) and ketoprofen group (G2)

\begin{tabular}{lcccccc}
\hline \multirow{2}{*}{$\begin{array}{c}\text { Parameter } \\
\text { Group }\end{array}$} & \multicolumn{7}{c}{ VAS score } \\
\cline { 2 - 8 } Time points & $\begin{array}{c}\text { Median } \\
\text { (paracetamol) }\end{array}$ & $\begin{array}{c}\text { G2 } \\
\text { (ketoprofen) }\end{array}$ & $\begin{array}{c}\text { G1 } \\
\text { (paracetamol) }\end{array}$ & $\begin{array}{c}\text { G2 } \\
\text { (ketoprofen) }\end{array}$ & $\begin{array}{c}\text { G1 } \\
\text { (paracetamol) }\end{array}$ & $\begin{array}{c}\text { G2 } \\
\text { (ketoprofen) }\end{array}$ \\
\hline T0 & 4.5 & 5.5 & 1.0 & 1.0 & 10.0 & 9.0 \\
\hline T1 & 4.0 & 5.0 & 1.0 & 1.0 & 10.0 & 9.0 \\
\hline T2 & 3.5 & 5.0 & 1.0 & 1.0 & 9.0 & 9.0 \\
\hline T3 & 3.0 & 4.5 & 1.0 & 1.0 & 9.0 & 8.0 \\
\hline T4 & 3.0 & 3.0 & 1.0 & 1.0 & 8.0 & 8.0 \\
\hline T5 & 3.0 & 3.0 & 0.0 & 1.0 & 6.0 & 8.0 \\
\hline T6 & $2.0 *$ & $2.0 *$ & 0.0 & 0.0 & 5.0 & 8.0 \\
\hline T7 & $2.0 *$ & $1.5 *$ & 0.0 & 0.0 & 5.0 & 4.0 \\
\hline T8 & $2.0 *$ & $1.0 *$ & 0.0 & 0.0 & 5.0 & 4.0 \\
\hline T9 & $2.0 *$ & $1.0 *$ & 0.0 & 0.0 & 7.0 & 8.0 \\
\hline T10 & $2.0 *$ & $1.0 *$ & 0.0 & 0.0 & 6.0 & 8.0 \\
\hline
\end{tabular}

*The statistically significant difference within one group $(p<0.05)$

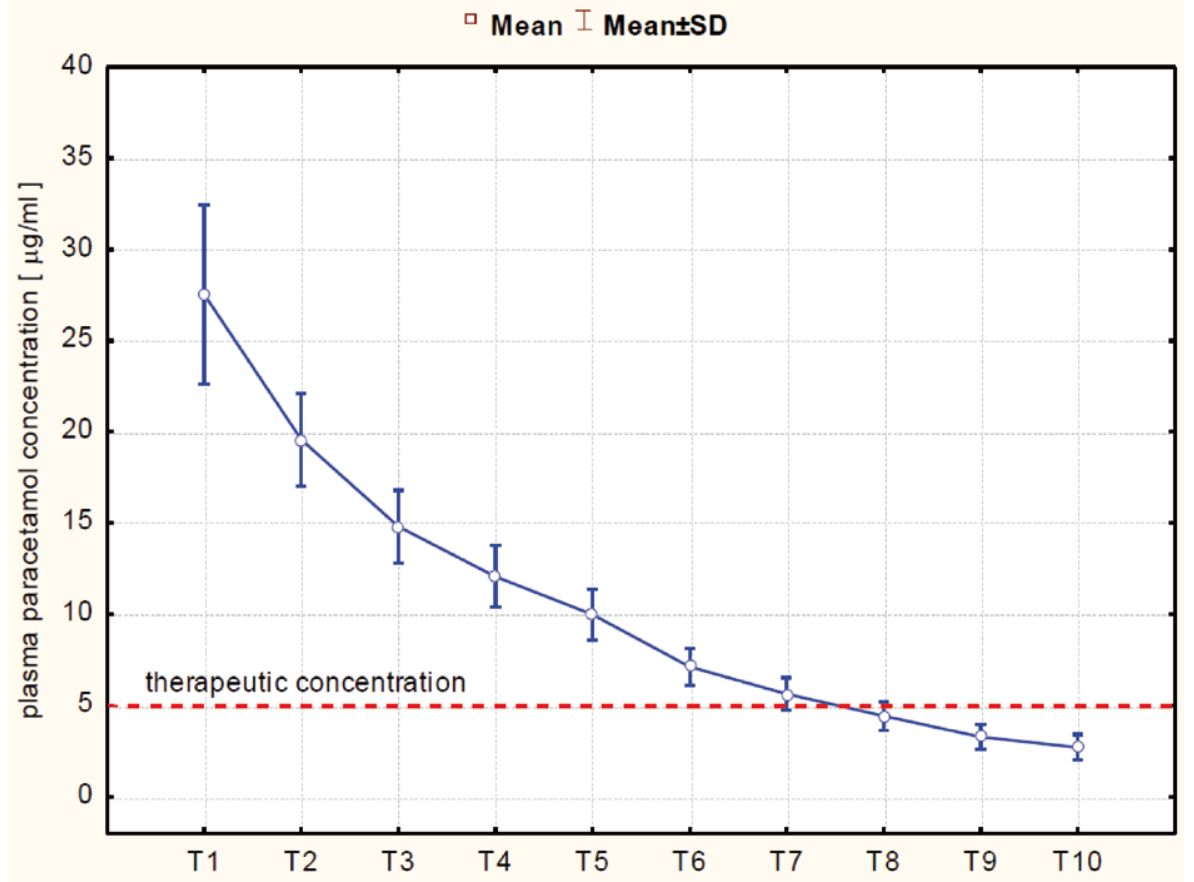

Figure 1. The mean values of paracetamol concentration

were observed for paracetamol than ketoprofen, whereas elimination phase $t_{1 / 2}$ was similar for both drugs.

The statistic analysis (ANOVA variation) of an influence of the age and body weight of patients to the above-mentioned parameters were calculated (Table 5). The only significant relation in the paracetamol group was found between body weight and MRT. In contrast, the statistically important dependence were shown between age and $\mathrm{AUC}_{\infty}$ or $\mathrm{MRT}_{\infty}$, body weight and $\mathrm{CL}, \mathrm{Vd}$ or $\mathrm{MRT}_{\infty}$ in the ketoprofen group.

Mean values of pharmacokinetic parameters obtained in our study were similar to those presented in the Flouvat survey (Table 6).

The mean concentration values of paracetamol and ketoprofen at each sampling time, and their direct comparison are presented in Figures 1, 2 and $\mathbf{3}$. 


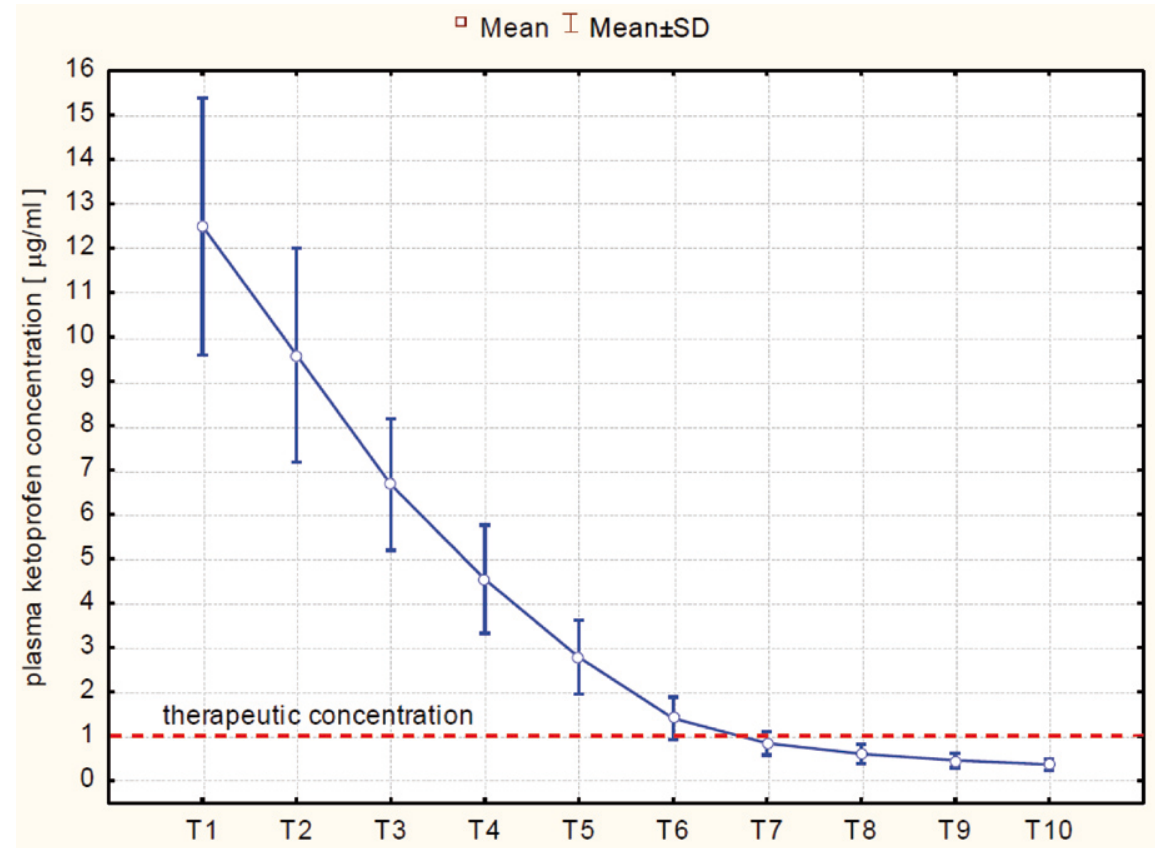

Figure 2. The mean values of ketoprofen concentration

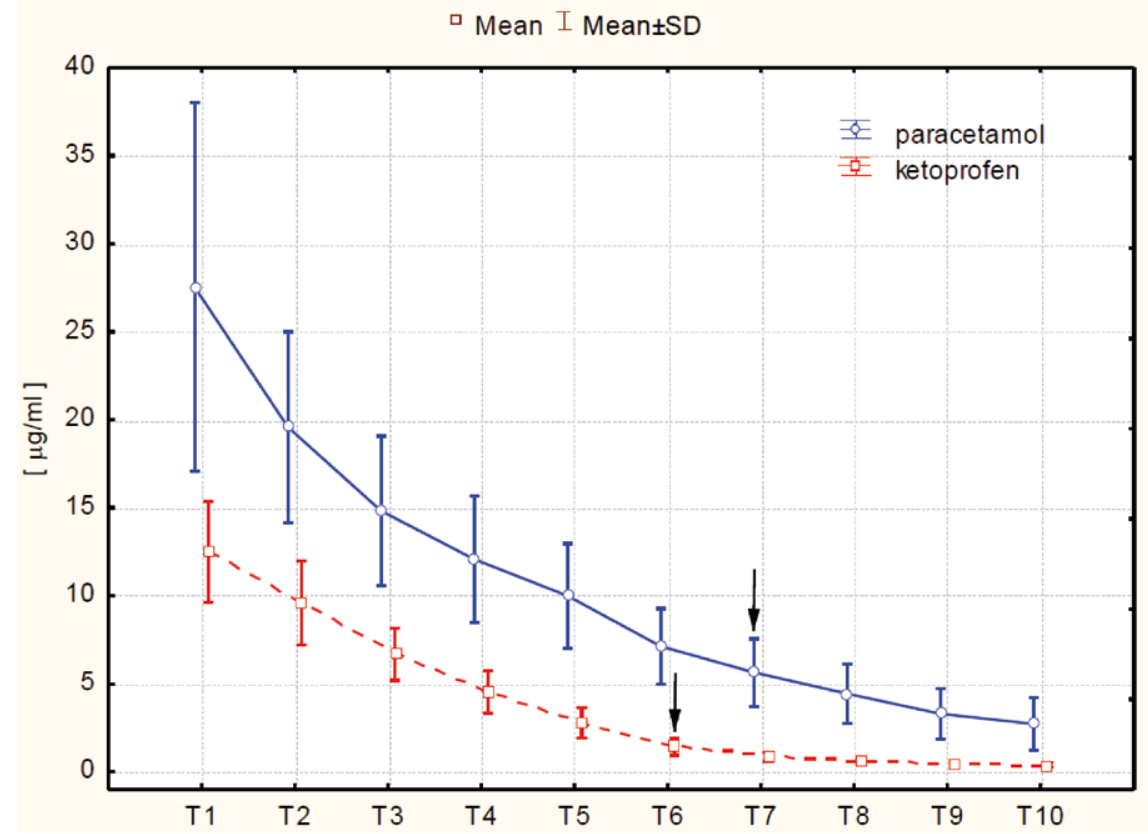

Figure 3. The mean concentration of paracetamol and ketoprofen (the pointers indicate the end of therapeutic concentration)

Table 4. The mean values of pharmacokinetic parameters of paracetamol and ketoprofen

\begin{tabular}{lcccccc}
\hline \multicolumn{1}{c}{ Parameter } & Mean $\pm \mathrm{SD}$ & Minimum & Maximum & Mean \pm SD & Minimum & Maximum \\
\hline $\mathrm{AUC}_{\infty}[\mathrm{mg} \cdot \mathrm{h} / \mathrm{l}]$ & $55.01 \pm 25.88$ & 23.78 & 135.91 & $13.11 \pm 3.25$ & 8.25 & 23.78 \\
\hline $\mathrm{Vd}[\mathrm{l}]$ & $84.88 \pm 33.15$ & 26.02 & 186.93 & $27.76 \pm 11.13$ & 12.90 & 54.68 \\
\hline $\mathrm{CL}[\mathrm{l} / \mathrm{h}]$ & $21.74 \pm 9.46$ & 7.36 & 60.89 & $8.02 \pm 1.81$ & 4.20 & 12.13 \\
\hline $\mathrm{t}_{1 / 2}[\mathrm{~h}]$ & $2.85 \pm 1.36$ & 1.42 & 6.45 & $2.36 \pm 0.07$ & 1.44 & 3.64 \\
\hline $\mathrm{MRT}_{\infty}[\mathrm{h}]$ & $4.04 \pm 1.84$ & 2.06 & 9.27 & $2.23 \pm 0.45$ & 1.64 & 3.05 \\
\hline
\end{tabular}

AUC 00 - the area under the plasma concentration-time curve, $\mathrm{Vd}-$ volume of distribution,

$\mathrm{CL}$ - the apparent total clearance, t1/2 - terminal phase half-life, MRToo - mean residence time 
Table 5. The statistic assessment ANOVA - the influence of body weight and patient's age on pharmacokinetic parameters of paracetamol and ketoprofen

\begin{tabular}{lcccc}
\hline & \multicolumn{2}{c}{ paracetamol } & \multicolumn{2}{c}{ ketoprofen } \\
\hline \multicolumn{1}{c}{ Parameter } & Age ( $\mathrm{p}$-value) & Body weight ( $\mathrm{p}$-value $)$ & Age ( $\mathrm{p}$-value) & Body weight ( $\mathrm{p}$-value) \\
\hline $\mathrm{AUC} \mathrm{C}_{\infty}$ & $>0.05$ & $>0.05$ & 0.0104 & $>0.05$ \\
\hline $\mathrm{CL}$ & $>0.05$ & $>0.05$ & $>0.05$ & 0.0124 \\
\hline $\mathrm{Vd}$ & $>0.05$ & $>0.05$ & $>0.05$ & $<0.0001$ \\
\hline $\mathrm{t}_{1 / 2}$ & $>0.05$ & $>0.05$ & $>0.05$ & $>0.05$ \\
\hline $\mathrm{MRT}_{\infty}$ & $>0.05$ & $<0.05$ & $<0.05$ & $<0.05$ \\
\hline
\end{tabular}

AUC $\infty$ - the area under the plasma concentration-time curve, $\mathrm{Vd}-$ volume of distribution

$\mathrm{CL}$ - the apparent total clearance, $\mathrm{t} 1 / 2$ - terminal phase half-life, MRTo - mean residence time

The $p$-values $<0.05$ indicate statistical significance

Table 6. The mean values of chosen pharmacokinetic parameters of paracetamol in our research in comparison to Flouvat survey

\begin{tabular}{lcccc}
\multicolumn{1}{c}{ Parameter } & $\begin{array}{c}\text { Minimum } \\
\text { Our research }\end{array}$ & $\begin{array}{c}\text { Maximum } \\
\text { Our research }\end{array}$ & $\begin{array}{c}\text { Mean } \pm \text { SD } \\
\text { Our research }\end{array}$ & $\begin{array}{c}\text { Mean } \pm \text { SD } \\
\text { Flouvat survey }\end{array}$ \\
\hline $\mathrm{AUC} \mathrm{C}_{\infty}[\mathrm{mg} \cdot \mathrm{h} / \mathrm{l}]$ & 23.78 & 135.91 & $55.01 \pm 25.88$ & $57.6 \pm 10.4$ \\
\hline $\mathrm{Vd}[\mathrm{l}]$ & 26.02 & 186.93 & $84.88 \pm 33.15$ & $69.2 \pm 8.6 \mathrm{I}$ \\
\hline $\mathrm{CL}[\mathrm{l} / \mathrm{h}]$ & 7.36 & 60.89 & $21.74 \pm 9.46$ & $17.9 \pm 3.4 \mathrm{I}$ \\
\hline $\mathrm{t}_{1 / 2}[\mathrm{~h}]$ & 1.42 & 6.45 & $2.85 \pm 1.36$ & $2.72 \pm 0.35$ \\
\hline
\end{tabular}

AUC $\infty$ - the area under the plasma concentration-time curve, $\mathrm{Vd}$ - volume of distribution,

$\mathrm{CL}$ - the apparent total clearance, $\mathrm{t} 1 / 2$ - terminal phase half-life

\section{Postoperative period}

The groups did not differ significantly in the number of perioperative side effects and complications. In $\mathrm{G} 1$ two patients $(10 \%)$ suffered from postoperative complications, i.e. haemorrhagic shock and iatrogenic pneumothorax. In G2 three patients (15\%) had postoperative side effects or complications, i.e. supraventricular arrhythmia, iatrogenic pneumothorax, acute ischemia of the lower extremity. None of local side effects or complications caused by the use of analgesic medications was noted in either group.

\section{Discussion}

Our study was comparing intravenous paracetamol with ketoprofen, an NSAID, in terms of clinical pharmacokinetics. Postoperative analgesia is an important factor relieving pain and decreasing complications. The additional use of non-steroidal analgesics decreases pain and it may also reduce the side effects caused by the use of opioids $[11,12]$. Sinatra and other authors documented the fact that the intensity of pain decreases significantly in the patients receiving an intravenous infusion of paracetamol or non-steroidal analgesics as a supplement to morphin in the PCA system, as compared with the use of morphine only in a monotherapy [13-15]. However, non-steroidal analgesics, such as ketoprofen, increase the effectiveness of opioid analgesia, but they cause numerous side effects. Ketopro- fen increases the risk of perioperative bleeding and the risk of renal dysfunction in patients with renal insufficiency [16-18].

Both Moller et al. and Sinatra et al. stated in their reports that the infusion of paracetamol did not have any clinically significant influence on the patients' haemodynamic parameters $[13,19,20]$. However, Peduto et al. in their research assessing the drug efficacy in orthopaedic surgery documented the fact that the heart rate in the group of patients receiving propacetamol was lower than in the group receiving a placebo, but the difference was not statistically significant [21]. In our study in the group of patients receiving paracetamol the heart rate ranged within the normal values during all periods of the research and it did not differ significantly between one another either after finishing the infusion or later. The average values of the mean arterial pressure ranged within the normal values during the whole study period, but they decreased after the end of infusion of the drug. However, these values were significantly greater than in the group receiving ketoprofen. Cusson et al. assessed the influence of ketoprofen on the blood pressure of patients suffering from arterial hypertension, who were treated with captopril and they found that it is safe to apply the drug to the patients only in a short-term therapy. The values of the patients' blood pressure were similar to those found in the patients receiving a placebo [22, 23].

Intravenous paracetamol is well tolerated by elderly people, including patients with high perioperative risk 
[24]. Our research proves this fact, because the average age in the group of patients who received paracetamol was $63.9 \pm 7.08$ years, III and IV class according to the ASA scale. Sinatra et al., whose findings were mentioned above, arrived at similar conclusions [13].

In our research the efficacy of paracetamol and ketoprofen as well as other methods of multimodal analgesia (PCA and epidural) was proved by low VAS values. According to the Visual Analogue Scale (VAS), after the infusion of the drug in $\mathrm{G} 179.5 \%$ of the results reached lower values than 4 , which proves the appropriate effectiveness of analgesia. Low VAS values remained until the end of the investigation in spite of the fact that the mean paracetamol concentration from the $240^{\text {th }}$ minute to the end of the infusion (T8) was lower than $5 \mu \mathrm{g} / \mathrm{ml}$ (Figure 1). The authors are of the opinion that it is the lower limit of the therapeutic concentration [25] On the other hand, in G2 after the infusion of the drug $73.5 \%$ of the results reached lower values than 4, according to the Visual Analogue Scale (VAS). The mean concentration of ketoprofen remained within the therapeutic range only until the $120^{\text {th }}$ minute after the end of the infusion (T6) and amounted to $1.41 \pm 0.48 \mu \mathrm{g} / \mathrm{ml}$. Główka et al. estimate the therapeutic concentration of ketoprofen at 1-5 $\mu \mathrm{g} / \mathrm{ml}$ (Figure 3) [26].

The paracetamol and ketoprofen groups did not differ significantly in the total dose of an opioid the patients applied during the period under investigation. Fletcher et al. arrived at similar conclusions in their study, which was mentioned above [27]. However, our research cannot assess the opioid-sparing effect of those analgesics, because there was no control group with a placebo available. The data from reference books prove the fact that in comparison with a placebo both paracetamol and ketoprofen decrease the demand for opioids [27-29]. Previous studies suggested that action of paracetamol might involve the opioidergic system but Pickering et al. in their pilot trial did not prove that yet [30].

The plasma paracetamol concentration which is required to achieve the necessary analgesia has not been fully investigated. It is thought that the therapeutic antipyretic concentration is $5-20 \mu \mathrm{g} / \mathrm{ml}$ [25]. Probably the plasma concentration which is necessary to achieve the analgesic effect needs to higher, although both higher and lower values are suggested [31]. In the article by Gibb and Anderson, published in March 2008, it is suggested that the necessary concentration to achieve the antipyretic effect is $5 \mu \mathrm{g} / \mathrm{ml}$, whereas it is $10 \mu \mathrm{g} / \mathrm{ml}$ for the analgesic effect [32].
The mean maximum values of plasma paraceta$\mathrm{mol}$ concentrations in the patients in this research were comparable with the results obtained by Flouvat et al., Murat et al. and with the values given by the drug manufacturer $[33,34]$. After the end of the infusion the mean maximum concentration of the drug was $27.53 \mu \mathrm{g} / \mathrm{ml}$ in our research, $29.9 \mu \mathrm{g} / \mathrm{ml}$ in Flouvat's and $30 \mu \mathrm{g} / \mathrm{ml}$ in Murat's. The latter value is the same as the one given by the manufacturer. Also, such pharmacokinetic parameters as: the total area under curve for time-dependent variations in the drug concentration $\left(A \cup C_{\infty}\right)$, the mean volume of distribution $(V d)$, the mean total clearance $(C L)$ or the half-life at the elimination stage $\left(t_{1 / 2}\right)$ did not differ significantly from the values obtained by Flouvat (Table 6). Flouvat researched a group of young healthy volunteers (aged 19-37 years), who neither received other drugs nor were anaesthetised immediately before the investigation. Hence the conclusion that the pharmacokinetic parameters and metabolism of paracetamol in elderly patients (the mean age of the patients in group I was $63.9 \pm 70.8$ years) with numerous preoperative burdens do not change and it is not necessary to modify the drug dosage to those patients.

Immediately after the end of the infusion the plasma paracetamol concentration was higher than $40 \mu \mathrm{g} /$ $\mathrm{ml}(40.84 \mu \mathrm{g} / \mathrm{ml}, 48.3 \mu \mathrm{g} / \mathrm{ml}$ and $53.08 \mu \mathrm{g} / \mathrm{ml})$ in three patients from group I. Prins et al. suggest that if the values of paracetamol concentration reach such a high level, this may potentially result in the hepatotoxic effect from the increased production of the toxic metabolite NAPQI involving the cytochrome P450 isoenzyme CYP2E1. However, Jackson et al. think that the risk of damage to the liver appears only when the plasma concentration exceeds $150 \mu \mathrm{g} / \mathrm{ml}$, which is much higher than the concentration from therapeutic doses [25].

Debruyne et al. studied the pharmacokinetics of ketoprofen after the intravenous administration of 100 $\mathrm{mg}$ of the drug and they obtained the following values of pharmacokinetic parameters: $\mathrm{AUC}_{\infty}$ - about 14 $\mathrm{mg} \cdot \mathrm{h} / \mathrm{l}, \mathrm{t}_{1 / 2}$ - about $2.5 \mathrm{~h}$ and $\mathrm{CL}$ - about $5.1 \mathrm{l} / \mathrm{h}$ [36]. These results are similar to the values obtained in this research, which may indicate that after the reconstructive surgery of the abdominal aorta the elimination of ketoprofen is not impaired. The statistical analysis proved the influence of body weight on the Vd parameter value. When the volume of distribution per $\mathrm{kg}$ of body weight value is calculated, a decrease in the inter-individual variation can be observed. The correlation between the $\mathrm{AUC}_{\infty}$ parameter and the patient's age was also proved. The bioavailability of the drug 
increases by 0.21 along with each consecutive year of life in the age group under investigation. On the other hand, the clearance value and the elimination half-life were not observed to decrease as the age increased.

Advenier et al. compared the pharmacokinetics of ketoprofen after the oral administration to younger and elderly people. They proved a significant increase in the values of the total area under the curve of variations in the time-dependent concentration of the drug $\left(\mathrm{AUC}_{\infty}\right)$ and $t_{1 / 2}$, but there was a decrease in CL. The patients' age span was much larger in that study, i.e. on average $24 \pm 1.3$ years in the group of younger patients and $86 \pm 2.4$ in the group of geriatric patients [37].

Our research findings do not point to the correlation between the patient's age and $\mathrm{AUC}_{\infty}, \mathrm{Vd}, \mathrm{CL}$ or $\mathrm{t}_{1 / 2}$ parameters for paracetamol. This is in agreement with the earlier data from reference books, which do not indicate the need to modify the dosage of the drug to elderly people [38].

Further clinical investigations are necessary to specify the place of intravenous paracetamol in pain therapy in different groups of patients. The drug has a wide range of advantages, which are particularly useful in the postoperative period. Our research findings also confirm the fact that after an intravenous administration the effect begins as soon as 5-10 minutes [8, 13, 39].

To sum up, intravenous paracetamol and ketoprofen administered to patients with moderate or severe postoperative pain after the reconstructive surgery of the abdominal aorta are effective, safe and well tolerated procedure.

The investigations in this study point to the fact that intravenous paracetamol and ketoprofen-are useful components of multimodal analgesia in the treatment of postoperative pain in patients after the reconstructive surgery of the abdominal aorta.

\section{Conclusion}

The study enabled the following conclusions: intravenous paracetamol as well as ketoprofen has good tolerability; there is no need to modify dosage to elderly patients and the therapeutic drug plasma concentration remains longer after a paracetamol infusion than after a ketoprofen infusion.

\section{Acknowledgements}

\section{Conflict of interest statement}

The authors declare no conflict of interest.

\section{Funding sources}

There are no sources of funding to declare.

\section{References}

1. Dolin SJ, Cashman JN, Bland JM. Effectiveness of acute postoperative pain management: I. Evidence from published data. Br J Anaesth. 2002;89:409-423.

2. Zukowski M, Kotfis K. The use of opioids adjuvants in perioperative multimodal analgesia. Anaesthesiol Intensive Ther. 2012;1;42-46.

3. Milewska MM, Horosz B, Ładyko AR. Pain-Free Hospital: Recommendation for the acute pain management in Poland. J Pain Relief. 2013;2:120 doi: 10.4172/21670846.1000120.

4. Manowska M, Bartkowska-Śniatkowska A, Zielińska M, Kobylarz K, Piotrowski A, Walas W et al. The consensus statement of the Paediatric Section of the Polish Society of Anaesthesiology and Intensive Therapy on general anaesthesia in children under 3 years of age. Anaesthesiol Intensive Ther. 2013;3:119-133.

5. Prescott LF. Paracetamol: past, present and future. Am J Ther. 2000;7:143-147.

6. Nikanne E, Kokki H, Tuovinen K. I.v. perioperative ketoprofen in small children during adenoidectomy. $\mathrm{Br}$ J Anaesth. 1997;78:24-27.

7. Kantor TG. Ketoprofen: a review of its pharmacologic and clinical properties. Pharmaco. 1986;6:93-103.

8. Whelton A. Renal and related cardiovascular effects of conventional and COX-2-specific NSAID and non-NSAID analgesics. Am J Ther. 2000;7:63-74.

9. Avouac B, Tule M. Ketoprofen: the European experience. J Clin Pharmacol. 1988;28:2-7.

10. Roda A, Sabatini L, Mirasoli M. Bioavilability of a new ketoprofen formulation for once-daily oral administration. Int J Pharm. 2002;8(241):165-172.

11. Kehlet H, Dahl JB. The value of "multimodal" or "balanced analgesia" in postoperative pain treatment. Anesth Analg. 1993;77:1048-1056.

12. Dahl JB, Rosenberg J, Dirkes WE. Prevention of postoperative pain by balanced analgesia. $\mathrm{Br} \mathrm{J}$ Anaesth. 1990;64:518-520.

13. Sinatra RS, Jahr JS, Reynolds LW. Efficacy and safety of single and repeated administration of 1 gram intravenous acetaminophen injection (paracetamol) for pain management after major orthopedic surgery. Anesthesiology. 2005;102:822-831.

14. Remy C, Marret E, Bonnet F. Effects of acetaminophen on morphine side-effects and consumption after major surgery: meta-analysis of randomized controlled trials. Br J Anaesth. 2005;94:505-513.

15. Basto ER, Waintrop C, Mourey FD. Intravenous ketoprofen in thyroid and parathyroid surgery. Anesth Analg. 2001;92:1052-1057.

16. Forrest JB, Camu F, Greer IA. Ketorolac, diclofenac, and ketoprofen are equally safe for pain relief after major surgery. Br J Anaesth. 2002;88:227-233.

17. Niemi TT, Taxell C, Rosenberg PH. Comparison of the effect of intravenous ketoprofen, ketorolac and diclofenac on platelet function in volunteers. Acta Anaesthesiol Scand. 1997;41:1353-1358.

18. Rugyte D, Kokki H. Intravenous ketoprofen as an adjunct to patient-controlled analgesia morphine in adolescents with thoracic surgery: a placebo controlled double-blinded study. Eur J Pain. 2007;11:694-699. 
19. Moller PL, Sindet-Pedersen S, Petersen CT. Onset of acetaminophen analgesia: comparison of oral and intravenous routes after third molar surgery. $\mathrm{Br} \mathrm{J}$ Anaesth. 2005;94:642-648

20. Moller PL, Juhl GI, Payen-Champenois C. Intravenous acetaminophen (paracetamol): comparable analgesic efficacy, but better local safety than its prodrug, propacetamol, for postoperative pain after third molar surgery. Anesth Analg. 2005;101:90-96.

21. Peduto VA, Ballabio M, Stefanini S. Efficacy of propacetamol in the treatment of postoperative pain. Morphine-sparing effect in orthopedic surgery. Italian Collaborative Group on Propacetamol. Acta Anaesthesiol Scand. 1998;42:293-298.

22. Cusson JR, du Souich P, Le Morvan P. Effect of ketoprofen on blood pressure, endocrine and renal responses to chronic dosing with captopril in patients with essential hypertension. Blood Press. 1992;1:162-167.

23. Cruz P, Garutti I, Díaz S. Metamizol versus propacetamol: comparative study of the hemodynamic and antipyretic effects in critically ill patients. Rev Esp Anestesiol Reanim. 2002;49:391-396.

24. Pettersson PH, Jakobsson J, Owall A. Plasma concentrations following repeated rectal or intravenous administration of paracetamol after heart surgery. Acta Anaesthesiol Scand. 2006;50:673-677.

25. Jackson CH, MacDonald NC, Cornett JW. Acetaminophen: a practical pharmacologic overview. Can Med Assoc J. 1984;131:25-32.

26. Główka FK, Karaźniewicz M. High performance capillary electrophoresis for determination of the enantiomers of 2-arylpropionic acid derivatives in human serum. Pharmacokinetic studies of ketoprofen enantiomers following administration of standard and sustained release tablets. J Pharm Biomed Anal. 2004;35:807-816.

27. Fletcher D, Negre I, Barbin C. Postoperative analgesia with iv propacetamol and ketoprofen combination after disc surgery. Can J Anaesth. 1997;44:479-485.

28. Delbos A, Boccard EJ. The morphine-sparing effect of propacetamol in orthopedic postoperative pain. Pain Symptom Manage. 1995;10:279-286.

29. Hernandez-Palazon J, Tortosa JA, Martinez-Lage JF. Intravenous administration of propacetamol reduces morphine consumption after spinal fusion surgery. Anesth Analg. 2001;92:1473-1476.

30. Pickering G, Moustafa F, Desbrandes S, Cardot JM, Roux D, Dubray C. Paracetamol and opioid pathways: a pilot randomized clinical trial. Fundam Clin Pharmacol. 2013;27:339-345
31. Pettersson PH, Owall A, Jakobsson J. Early bioavailability of paracetamol after oral or intravenous administration. Acta Anaesthesiol Scand. 2004;48:867-870.

32. Gibb IA, Anderson BJ. Paracetamol (acetaminophen) pharmacodynamics: interpreting the plasma concentration. Arch Dis Child. 2008;93:241-247.

33. Flouvat B, Leneveu A, Fitoussi S. Bioequivalence study comparing a new paracetamol solution for injection and propacetamol after single intravenous infusion in healthy subjects. Int J Clin Pharmacol Ther. 2004;42:50-57.

34. Murat I, Baujard C, Foussat C. Tolerance and analgesic efficacy of a new i.v. paracetamol solution in children after inguinal hernia repair. Paediatr Anaesth. 2005; 15:663-670.

35. Prins SA, Van Dijk M, Van Leeuwen P. Pharmacokinetics and analgesic effects of intravenous propacetamol vs rectal paracetamol in children after major craniofacial surgery. Paediatr Anaesth. 2008;18(7):582-592.

36. Debruyne D, Hurault de Ligny B, Ryckelynck JP. Clinical pharmacokinetics of ketoprofen after single intravenous administration as a bolus or infusion. Clin Pharmacokinet. 1987;12:214-221.

37. Advenier C, Roux A, Gobert C. Pharmacokinetics of ketoprofen in the elderly. Br J Clin Pharmacol. 1983;16:65-70.

38. Divoll M, Abernethy DR, Ameer B. Acetaminophen kinetics in elderly. Clin Pharmacol Ther. 1982;31:151-156.

Acceptance for editing: 2016-12-10 Acceptance for publication: 2016-12-22 